\title{
INTERthesis
}

DOUTORADO INTERDISCIPLINAR EM CIÊNCIAS HUMANAS - UFSC - FLORIANÓPOLIS - SC - BRASIL

\section{VIOLÊNCIA DOMÉSTICA E FAMILIAR CONTRA AS MULHERES: POLÍTICAS PÚBLICAS E DELEGACIAS ESPECIALIZADAS EM SANTA CATARINA}

\author{
Leandro Alfredo da Rosa ${ }^{1}$ \\ Giovana Ilka Jacinto Salvaro² \\ Ismael Gonçalves Alves ${ }^{3}$
}

\section{Resumo:}

Este artigo busca analisar, de acordo com a Lei 11.340/2006 (BRASIL, 2006), a implementação de políticas de atendimento a mulheres em situação de violência doméstica e familiar no âmbito das Delegacias Especializadas de Santa Catarina. Para o desenvolvimento da pesquisa, foi utilizado material bibliográfico e documental, envolvendo a literatura especializada sobre o tema e o levantamento de dados em bases especializadas/oficiais do estado de Santa Catarina. Por meio do levantamento realizado e da análise, foi possível verificar a instalação de Delegacias de Proteção à Criança, Adolescente, Mulher e Idoso (DPCAMIs), distribuídas nas regiões da grande Florianópolis, Oeste, Serrana, Sul do Estado e Vale do Itajaí. No entanto, é preciso atentar para o fato de que as diretrizes orientam para a criação de Delegacias de Atendimento à Mulher.

Palavras-chave: Violência Doméstica e Familiar. Violência de Gênero. Políticas Públicas. Lei 11.340/2006. Delegacias de Atendimento à Mulher.

\section{DOMESTIC AND FAMILY VIOLENCE AGAINST WOMEN: PUBLIC POLICIES AND SPECIALIZED POLICE STATIONS IN SANTA CATARINA STATE}

\begin{abstract}
:
By the Law 11.340 / 2006 (BRAZIL, 2006), this article seeks to analyze the implementation of public policies to assist women in situations of domestic and family violence within the Specialized Police Stations of Santa Catarina. The methods used are bibliographical and documentary research, including specialized literature on the subject, and data collection in specialized official databases of the state of Santa Catarina. Through this analysis, it was possible to verify the implementation of Police Stations for the Protection of Children, Adolescents, Women and the Elderly (DPCAMIs in Portuguese), distributed in the regions the Florianópolis, Oeste, Serrana, South of the State and Itajaí Valley. However, we must pay attention to the fact that the guidelines aim at the creation of Police Stations for Women.
\end{abstract}

\footnotetext{
${ }^{1}$ Bacharel em Direito pela Universidade do Sul de Santa Catarina; Especialista em Ciências Penais pela Universidade do Sul de Santa Catarina. Professor curso de Direito da Universidade do Extremo Sul Catarinense, Criciúma, SC, Brasil E-mail: leandrodarosa@unesc.net

2 Doutora em Ciências Humanas pela Universidade Federal de Santa Catarina. Professora do Programa de Pós-Graduação em Desenvolvimento Socioeconômico e do Programa de Pós-Graduação em Direito da Universidade do Extremo Sul Catarinense, Criciúma, SC, Brasil E-mail: giovanailka@gmail.com

${ }^{3}$ Doutor em História, pela Universidade Federal do Paraná, Curitiba, PR. Professor permanente do Programa de Pós-Graduação em Desenvolvimento Socioeconômico da Universidade do Extremo Sul Catarinense, Criciúma, SC, Brasil E-mail: iga@unesc.net
} 
Keywords: Domestic and Family Violence. Gender Violence. Public Policy. Law 11.340/2006. Police Stations for Women.

\section{VIOLENCIA DOMÉSTICA Y FAMILIAR CONTRA LAS MUJERES, POLÍTICAS PÚBLICAS Y COMISARÍAS ESPECIALIZADAS EN SANTA CATARINA}

\section{Resumen:}

Este artículo busca analisar, de acuerdo con la Ley 11.340 / 2006 (BRASIL, 2006), la implementación de políticas de atención a mujeres en situación de violencia doméstica y familiar en el ámbito de las Comisarías Especializadas de Santa Catarina. Para el desarrollo de la investigación, se utilizó material bibliográfico y documental, envolviendo la literatura especializada sobre el tema y el levantamiento de datos en bases especializadas/oficiales del estado de Santa Catarina. Por medio del levantamiento realizado y del análisis, fue posible verificar la instalación de Comisarías de Protección al Niño, al Adolescente, a la Mujer y al Adulto Mayor (DPCAMIs, por su sigla en portugués), distribuidas en las regiones de la gran Florianópolis, Oeste, Serrana, Sur del Estado y Valle del Itajaí. Sin embargo, hay que prestar atención al hecho de que las directrices orientan hacia la creación de Comisarías de Atención a la Mujer.

Palabras-clave: Violencia Doméstica y Familiar. Violencia de Género. Políticas Públicas. Ley 11.340 / 2006. Comisarías de Atención a la Mujer.

\section{INTRODUÇÃO}

A implementação de políticas de atendimento a mulheres em situação de violência doméstica e familiar no âmbito das Delegacias Especializadas não se apresenta como um novo tema, mas requer estudos continuados, conforme evidenciam algumas das pesquisas realizadas antes e depois da promulgação da Lei 11.340/2006 (DEBERT; GREGORI, 2002; PASINATO, 2005; DEBERT, 2006; SANTOS, 2010; BARSTED; PITANGUY, 2013; SANTOS, 2015; CAMPOS, 2015).

Em artigo que trata da absorção/tradução de demandas feministas pelo Estado brasileiro, no que se refere ao combate à violência doméstica contra as mulheres, a partir da década de 1980, Santos (2010, p. 155) identifica três momentos: "[...] primeiro, o momento da criação das delegacias da mulher, em 1985; segundo, o do surgimento dos Juizados Especiais Criminais, em 1995; terceiro, o do advento da Lei 11.340, de 7 de agosto de 2006, a chamada Lei Maria da Penha”.

A divisão temporal apresentada pela autora demonstra que o enfrentamento da violência contra as mulheres exigiu posicionamentos do Estado brasileiro diante de um contexto histórico de lutas feministas. Na reflexão em questão, ressalta-se a criação das delegacias e a promulgação da Lei 11.340/2006 como os momentos que provocaram importantes mudanças no tratamento da violência contra as mulheres pelo Estado. Apesar disso, a implementação da Lei Maria da Penha revela obstáculos 
que demonstram avanços parciais, como, por exemplo, o foco em "[...] medidas criminais e na constitucionalidade da lei, levando alguns agentes do Estado a uma tradução restrita da nova legislação". (SANTOS, 2010, p. 155, grifos da autora).

Em grande medida, a denúncia da gravidade da situação envolvendo a violência doméstica e familiar contra as mulheres e a necessidade de implementação de políticas eficazes de enfrentamento, que se busca analisar, justificam-se pelos índices de violências. Como representativo de um cenário extremamente preocupante, o Mapa da Violência de 2015 (WAISELFISZ, 2015, p. 69-70) apresenta uma estimativa do número de feminicídios no Brasil a partir dos dados de homicídios de mulheres, conforme demonstrado:

Dos 4.762 homicídios de mulheres registrados em 2013 pelo SIM, 2.394, isso é, $50,3 \%$ do total nesse ano, foram perpetrados por um familiar da vítima. [...] 1.583 dessas mulheres foram mortas pelo parceiro ou ex-parceiro, o que representa $33,2 \%$ do total de homicídios femininos nesse ano.

Em tal direção, como parte da pesquisa realizada na dissertação de mestrado (DA ROSA, 2019), concluída no primeiro semestre de 2019, neste artigo, de acordo com a Lei 11.340/2006 (BRASIL, 2006), busca-se analisar a implementação de políticas de atendimento a mulheres em situação de violência doméstica e familiar no âmbito das Delegacias Especializadas de Santa Catarina. Para a realização da pesquisa, foi utilizado material bibliográfico e documental, envolvendo a literatura especializada sobre o tema e o levantamento de dados em bases oficiais do estado de Santa Catarina.

Como foco central do debate, trata-se de problematizar a política pública de atendimento a partir da previsão estabelecida pela Lei 11.340/2006 e da Norma Técnica de Padronização das Delegacias Especializadas de Atendimento às Mulheres - DEAMs (BRASIL, 2010). Compreende-se que o enfoque se faz necessário para lançar um olhar sobre a realidade catarinense, uma vez que as Delegacias Especializadas se constituem uma das portas de entrada para que as mulheres em situação de violência, pela tomada de decisão e denúncia, enfrentem o ciclo da violência, contribuindo para mudanças significativas na sua e na vida de toda a família.

Nesse sentido, para o debate proposto, optou-se pela organização do artigo em duas seções temáticas, por meio das quais, com base nas normativas já citadas, são tratadas questões relativas a políticas públicas de atendimento a mulheres em situação de violências, com foco nas Delegacias Especializadas em Santa Catarina. 


\title{
2 POLÍTICAS PÚBLICAS DE ATENDIMENTO A MULHERES EM SITUAÇÃO DE VIOLÊNCIA DOMÉSTICA E FAMILIAR NO ÂMBITO DA LEI 11.340/2006
}

A política pública pode ser compreendida, de acordo com Souza (2006, p. 26), "[...] como o campo do conhecimento que busca, ao mesmo tempo, 'colocar o governo em ação' e/ou analisar essa ação (variável independente) e, quando necessário, propor mudanças no rumo ou curso dessas ações (variável dependente)". Segundo a autora, a política pública possui um ciclo de criação formado por vários estágios, em um processo dinâmico e de aprendizado, constituído de diversas etapas a serem alcançadas, a saber: definição de agenda, identificação de alternativas, avaliação das opções, seleção das opções, implementação e avaliação (SOUZA, 2006).

No campo das políticas públicas de atendimento a mulheres em situação de violência doméstica e familiar, é central a compreensão de etapas da trajetória de formulação e mecanismos dispostos pela Lei 11.340/2006, promulgada em 07 de agosto de 2006 e popularmente chamada de Lei Maria da Penha (LMP). No preâmbulo, destacam-se os objetivos:

\begin{abstract}
Cria mecanismos para coibir a violência doméstica e familiar contra a mulher, nos termos do $\S 80$ do art. 226 da Constituição Federal, da Convenção sobre a Eliminação de Todas as Formas de Discriminação contra as Mulheres e da Convenção Interamericana para Prevenir, Punir e Erradicar a Violência contra a Mulher; dispõe sobre a criação dos Juizados de Violência Doméstica e Familiar contra a Mulher; altera o Código de Processo Penal, o Código Penal e a Lei de Execução Penal; e dá outras providências. (BRASIL, 2006).
\end{abstract}

De acordo com o texto disposto, a Lei 11.340/2006 deve ser considerada em uma trajetória de luta envolvendo movimentos feministas e de mulheres, articulada a um cenário brasileiro de ratificação de importantes documentos internacionais, tais como a "Convenção sobre a Eliminação de Todas as Formas de Discriminação contra a Mulher (CEDAW)" e a "Convenção Interamericana para Prevenir, Punir e Erradicar a Violência contra a Mulher (Convenção de Belém do Pará, 1994)", conforme ressaltam Calazans e Cortes (2011, p. 56).

Em uma concepção internacional de direitos humanos, na Convenção de Belém do Pará, a violência contra as mulheres é tratada como uma violação de tais direitos, "[...] considerando que o privado é público e, por consequência, cabe aos Estados assumirem a responsabilidade e o dever indelegável de erradicar e sancionar as situações de violência contra as mulheres". (BANDEIRA; ALMEIDA, 2015, p. 506).

No processo de elaboração da LMP, destaca-se a atuação do Consórcio de Organizações Não Governamentais (ONGs) feministas e da Secretaria de Política 
para as Mulheres (SPM), (BANDEIRA; ALMEIDA, 2015). O processo envolveu a denúncia oferecida pela Sra. Maria da Penha Fernandes (vítima em duas oportunidades de tentativa de homicídio praticada por seu ex-marido) e enviada à Comissão Interamericana de Direitos Humanos (CIDH) da Organização dos Estados Americanos (OEA), em abril de 2001, conjuntamente, pelo Centro de Justiça e Direito Internacional (Cejil) e pelo Comitê Latino-Americano de Defesa dos Direitos da Mulher (Cladem), (BANDEIRA; ALMEIDA, 2015).

As autoras ressaltam que, em razão da denúncia, a CIDH detectou que o Brasil havia descumprido a Convenção Americana de Direitos Humanos e a Convenção de Belém do Pará no que se referia ao direito de defesa e investigação rigorosa dos agressores. A análise do caso pela Comissão concluiu que "[...] o Brasil não garantiu um processo justo contra o agressor em um prazo razoável." (BANDEIRA; ALMEIDA, 2015, p. 506). As recomendações da CIDH remeteram ao descumprimento do artigo $7^{\circ}$ da Convenção de Belém do Pará e dos artigos $1^{\circ}, 8^{\circ}$ e $25^{\circ}$ da Convenção Americana de Direitos Humanos e à adoção, pelo Brasil, de medidas de combate à violência contra a mulher, incluindo a elaboração de uma lei específica (CALAZANS; CORTES, 2011).

Em texto que trata da LMP como uma ação bem-sucedida de advocacy feminista, Barsted (2011, p. 15) argumenta que "[...] a luta pelo direito a uma vida sem violência, que possibilitou a aprovação da Lei Maria da Penha, em 2006, é um caso exemplar de exercício de uma cidadania ativa expressa no discurso e na atuação das feministas no espaço público". Como visto, no campo das etapas de elaboração da política pública, aspectos singulares marcaram as trajetórias de criação e de aprovação da LMP, assim como suscitaram mudanças significativas no tratamento da violência doméstica e familiar contra as mulheres. Além dos aspectos relacionados ao modo como foi concebida, Campos (2017, p. 12) observa "[...] inovações no campo jurídico e das políticas públicas [...]", uma vez que alteram formas de lidar em situações de violência doméstica.

\footnotetext{
Essas modificações que propugnam por um tratamento/atendimento integral, intersetorial e interdisciplinar aos casos de violência doméstica provocam um profundo mal-estar nas instituições jurídicas, acostumadas a lidar com a violência doméstica contra mulheres como delito de menor potencial ofensivo e quase privado ou como no modelo tradicional - autoria - evidência (prova) do crime. (CAMPOS, 2017, p. 12-13).
}

Diante das questões destacadas, é fundamental, então, atentar para o fato de que a efetividade da LMP se articula com um conjunto de medidas a serem aplicadas 
com o intuito de fomentar um tratamento/atendimento em consonância com as mudanças suscitadas. Uma das mudanças significativas inclui a própria forma de compreensão da violência doméstica e familiar contra as mulheres, conforme disposto no Art. $5^{\circ}$, no Título II (Da Violência Doméstica e Familiar contra a Mulher), Capítulo I (Das Disposições Gerais):

Art. 5 o Para os efeitos desta Lei, configura violência doméstica e familiar
contra a mulher qualquer ação ou omissão baseada no gênero que lhe cause
morte, lesão, sofrimento físico, sexual ou psicológico e dano moral ou
patrimonial:
I - No âmbito da unidade doméstica, compreendida como o espaço de
convívio permanente de pessoas, com ou sem vínculo familiar, inclusive as
esporadicamente agregadas;
II - No âmbito da família, compreendida como a comunidade formada por
indivíduos que são ou se consideram aparentados, unidos por laços naturais,
por afinidade ou por vontade expressa;
III - Em qualquer relação íntima de afeto, na qual o agressor conviva ou tenha
convivido com a ofendida, independentemente de coabitação.
Parágrafo único. As relações pessoais enunciadas neste artigo independem
de orientação sexual. (BRASIL, 2006).

Em conformidade com o Art. $5^{\circ}$, a violência doméstica e familiar contra a mulher compreende uma perspectiva de gênero, posto que a violência sofrida se relaciona ao fato de a vítima ser uma mulher. Bandeira (2014, p. 450), refere se tratar de uma violência que "[...] ocorre motivada pelas expressões de desigualdades baseadas na condição de sexo, a qual começa no universo familiar, onde as relações de gênero se constituem no protótipo de relações hierárquicas".

Em análise crítica da descrição do gênero como categoria analítica, Nicholson (2000) ressalta o uso de duas maneiras (ou dois sentidos) diferentes e, às vezes, contraditórias: 1) como oposição ao sexo e para tratar do que é socialmente construído; 2) construção social que distingue o masculino do feminino, envolvendo as construções que diferenciam tais corpos. A autora ressalta a necessidade de remontar a origem do termo "gênero", que "[...] tem suas raízes na junção de duas ideias importantes do pensamento ocidental moderno: a da base material da identidade e a da construção do caráter humano" (NICHOLSON, 2000, p. 10). Ademais, é central atentar para as questões de poder envolvidas nas "[...] dinâmicas dessimétricas das relações de gênero [...]" e como elas se interseccionam com "[...] classe, raça e idade [...]" (DEBERT; GREGORI, 2008, p. 166).

Logo, coibir a violência doméstica e familiar contra as mulheres, entre outros aspectos, exige uma complexa articulação de mecanismos para o seu enfretamento, como pode ser observado no Título III da Lei, que trata da Assistência à Mulher em 
situação de violência doméstica e familiar, Capítulo I - Das Medidas Integradas de Prevenção, conforme disposto no Art. 80: "A política pública que visa coibir a violência doméstica e familiar contra a mulher far-se-á por meio de um conjunto articulado de ações da União, dos Estados, do Distrito Federal e dos Municípios e de ações nãogovernamentais [...]" (BRASIL, 2006). De um modo apurado, percebe-se que o Art. $8^{\circ}$ estabelece políticas públicas com ampla abrangência, como a interação entre vários órgãos e ações em rede. De acordo com o documento da Rede de Enfrentamento à Violência contra as Mulheres, oriundo da Secretaria Especial de Políticas para Mulheres - SPM (BRASIL, 2011a, p. 14), as redes compreendem "[...] ações e serviços de diferentes setores (em especial, da assistência social, da justiça, da segurança pública e da saúde), que visam à ampliação e à melhoria da qualidade do atendimento [...]".

No capítulo III - Do Atendimento pela Autoridade Policial -, verifica-se a necessidade de implementação de atendimento para as mulheres em Delegacias Especializadas, além de campanhas educativas voltadas à prevenção da violência doméstica e familiar contra as mulheres nas escolas e na sociedade em geral, capacitação de modo permanente das Polícias Civil e Militar, da Guarda Municipal, do Corpo de Bombeiros e dos profissionais ligados à Segurança Pública quanto às questões de gênero, de raça ou de etnia, bem como destaque em currículos escolares em todos os níveis de ensino para conteúdos relativos aos direitos humanos, equidade de gênero, de raça ou de etnia e ao problema da violência doméstica contra a mulher (BRASIL, 2006).

Farah (2004, p. 52) destaca que os movimentos pressionaram esferas do governo de acordo com cada competência governamental e campo de política pública, sendo que, "[...] por exemplo, as reivindicações na área de combate à violência contra a mulher se dirigiram prioritariamente aos níveis estadual e municipal”.

O processo de incorporação de tal problemática a propósito da violência contra as mulheres, nos últimos anos, pode ser verificado nos Planos Nacionais de Políticas para as Mulheres - PNPM 2004-2015 (BRASIL, 2004; 2008; 2013), os quais apresentaram eixos que tratavam especificamente da violência contra as mulheres e de direcionamentos relacionados ao atendimento. Além disso, destacam-se o Pacto e a Política Nacional pelo Enfrentamento à Violência contra as Mulheres (BRASIL, 2011 b; 2011c). O conjunto das Políticas Nacionais citadas está relacionado à Secretaria de Políticas para as Mulheres (SPM), criada em 2003, como marco no 
enfrentamento à violência contra as mulheres quanto à elaboração de políticas públicas especificas "[...] conceitos, diretrizes, normas e da definição de ações e estratégias de gestão e monitoramento relativas à temática." (BRASIL, 2011b, p. 9).

Como parte do processo de enfrentamento da violência doméstica e familiar contra as mulheres, "[...] a intervenção deve se caracterizar pela promoção e implementação de políticas públicas de responsabilidade dos governos federal, estaduais e municipais, constituindo uma rede de ações e serviços." (BRASIL, 2004, p. 75). A rede de ações e serviços abrange as esferas jurídica, social, da saúde, da educação e do trabalho, as quais devem ser ofertadas por "Delegacias Especializadas de Atendimento à Mulher, delegacias comuns, Centro de Referência, Defensorias Públicas da Mulher, Defensorias Públicas, Instituto Médico Legal, Serviços de Saúde, Polícia Militar, Corpo de Bombeiros, Casas Abrigos." (BRASIL, 2004, p. 75).

Portanto, as Delegacias Especializadas de Atendimento à Mulher (DEAMs) integram o conjunto das políticas públicas de atendimento a mulheres em situação de violência doméstica e familiar. Na sequência, conforme objetivo do texto, são apresentadas algumas considerações sobre a implementação de Políticas de Atendimento a Mulheres em situação de violência doméstica e familiar no âmbito das Delegacias Especializadas de Santa Catarina.

\section{DELEGACIAS ESPECIALIZADAS DE ATENDIMENTO ÀS MULHERES EM SANTA CATARINA: CONSIDERAÇÕES A PARTIR DA LEI 11.340/2006}

Santos (2015, p. 580) observa que "[...] a primeira delegacia da mulher foi criada na cidade de São Paulo, em agosto de 1985, num contexto de redemocratização política e de intensas mobilizações feministas pelo reconhecimento dos direitos das mulheres". De acordo com Debert (2006, p. 16), as primeiras Delegacias de Polícia de Defesa da Mulher (DDMs) representaram "[...] uma invenção pioneira brasileira que depois se expandiu para outras cidades do país e para outros países da América Latina".

No Brasil, a criação das delegacias "[...] foi a primeira experiência de implementação de uma política pública de combate à violência contra as mulheres [...]", conforme registrou o documento da Norma Técnica de Padronização das Delegacias Especializadas de Atendimento às Mulheres (DEAMs), edição atualizada em 2010, (BRASIL, 2010, p. 7). Como visto no tópico anterior, as ações e serviços do 
setor de segurança pública integram a rede de atendimento a mulheres em situação de violência, (BRASIL, 2011a).

Desde a sua criação, portanto, verifica-se um aumento no número de delegacias da mulher, bem como de outros serviços especializados que compõem a rede de enfrentamento à violência contra as mulheres. No entanto, é central assinalar que "[...] referidas pelo acrônimo DDM em São Paulo ou DEAM no país, desde então foram criadas centenas de delegacias da mulher no Brasil, embora a maior parte concentre-se na Região Sudeste", (SANTOS, 2015, p. 580).

Em uma perspectiva mais ampla de atendimento, os dados apresentados no documento da Rede de Enfrentamento à Violência contra as Mulheres (BRASIL, 2011a, p. 17-18) demonstraram que ocorreu um aumento de $161,75 \%$, entre 2003 e 20 de setembro de 2011, no conjunto de serviços especializados, a saber: "359 Delegacias Especializadas de Atendimento à Mulher, 187 Centros de Referência de Atendimento à Mulher, 72 Casas-Abrigo, 57 Defensorias Especializadas, 48 Promotorias Especializadas".

Em artigo que analisa as conclusões da Comissão Parlamentar Mista de Inquérito (CPMI) da Violência contra a Mulher (Criada pelo requerimento $n^{\circ} 4 / 2011$ e instalada em março de 2012) no âmbito da aplicação da Lei Maria da Penha, Campos (2015, p. 522) ressalta que, no Brasil, no período de análise, segundo o Relatório Final da CPMI (BRASIL, 2013), existiam 202 Centros de Referência de Atendimento da Mulher, 71 casas abrigo, 66 juizados especializados, 27 Varas adaptadas, 64 promotorias especializadas e 36 núcleos ou defensorias especializadas; contudo os números são inferiores ao que exige a demanda. No Brasil, no ano de 2012, o total de Delegacias da Mulher (DEAMs) atingia 443, número considerável em comparação com outros serviços, o que aponta o quanto a política pública de atendimento às mulheres focou sua atuação na esfera policial, tornando-se o primeiro serviço e a primeira política de segurança pública dirigida às mulheres, (CAMPOS, 2015).

A propósito das Delegacias Especializadas de Atendimento à Mulher (DEAMs), é necessário pontuar a política pública, sobretudo no âmbito das lutas feministas, que materializou o reconhecimento da violência contra as mulheres como crime e chamou à responsabilidade o Estado acerca da implantação de políticas públicas na seara da violência contra as mulheres, (SOUZA; CORTEZ, 2014).

Com a entrada em vigor da Lei 11.340/2006, mudanças significativas foram percebidas na criação de novas atribuições no que diz respeito ao atendimento em 
Delegacias Especializadas. Sendo assim, as mudanças demandaram a criação de uma diretriz para a estruturação das unidades policiais, por meio das Normas Técnicas de Padronização das Delegacias Especializadas de Atendimento às Mulheres - DEAMs, (BRASIL, 2010).

O documento referenciado, além da apresentação, da introdução, das considerações finais, das recomendações e do anexo, é composto por cinco capítulos, envolvendo conteúdos normativos, conceituais, técnicos e estruturais, conforme intitulado: (1) Lei Maria da Penha: um novo marco normativo; (2) diretrizes das DEAMs; (3) princípios e novas atribuições das DEAMs em conformidade com a Lei Maria da Penha; (4) rede de serviços de atendimento a mulheres em situação de violência; (5) estrutura das DEAMs. O documento dispõe que "[...] as DEAMs compõem a estrutura da Polícia Civil, órgão integrante do Sistema de Segurança Pública de cada Estado [...]", (BRASIL, 2010, p. 28).

Em artigo sobre as Delegacias das Mulheres em Santa Catarina, Oliveira e Ghisi (2019, p. 4) evidenciam que "[...] no organograma da Polícia Civil de Santa Catarina, não se encontram especificadas as unidades que correspondem às Delegacias da Mulher, haja vista que elas são consideradas, em estrutura e hierarquia, como uma Delegacia de Polícia de Comarca (DPCo)". No entanto, esclarecem que existem delegacias especializadas na apuração de diferentes tipos de crimes, dentre as quais as Delegacias de Proteção à Criança, Adolescente, Mulher e Idoso.

Em Santa Catarina, especificamente na capital Florianópolis, foi criada a segunda Delegacia Especializada da Mulher do País (considerando, conforme já citado, que a primeira foi a Delegacia da Mulher de São Paulo, criada em 1985), com base no Decreto Estadual no 19.273/83, de 11 de abril de 1983, (OLIVEIRA; GHISI, 2019). Ao longo dos anos, outras unidades especializadas foram criadas em Santa Catarina para atender "[...] mulheres, crianças e idosos, a partir da publicação, no Diário Oficial do Estado no dia 14 de janeiro de 2004, da Resolução 007/GAB/CPC/SSP/2003, revogada pela Resolução n 008/GAB/DGPC/SSP/2013, de 07 de outubro de 2013." (OLIVEIRA; GHISI, 2019, p. 05).

Para a análise em questão, é importante ressaltar o que registram as autoras sobre a não diferenciação dos crimes de violência doméstica de outros crimes comuns no serviço de atendimento nas referidas delegacias. Em tal estrutura de atendimento, portanto, "[...] o que orienta a atribuição da delegacia é o sexo sujeito passivo: se for 
mulher, vítima de qualquer violência física ou moral praticada por homem, deve ser atendida na unidade", (OLIVEIRA; GHISI, 2019, p. 05).

Além disso, cabe registrar que, no estado de Santa Catarina, tem-se a denominação Delegacia de Proteção à Criança, ao Adolescente, à Mulher e ao Idoso (DPCAMI), sendo atribuída, administrativamente, em 2008, com o objetivo de "[...] garantir uma padronização mínima", (OLIVEIRA; GHISI, 2019, p. 8). Acerca da não padronização e de especificidades que marcam a organização/funcionamento das delegacias especializadas em cada estado, o relatório do Observatório pela Aplicação da Lei Maria da Penha (OBSERVE, 2010, p. 32) apresenta o seguinte registro:

\begin{abstract}
A localização das DEAMS no organograma das Polícias Civis varia de estado para estado. Em alguns casos, são alocadas em divisões ou departamentos, em conjunto com outras delegacias especializadas - do idoso, da criança e do adolescente, por exemplo; em outros, estão subordinadas às delegacias seccionais. Um dos grandes problemas que afeta o funcionamento das DEAMS e tem se constituído como obstáculo para a aplicação da Lei $11.340 / 2006$ é a falta de padronização na forma de funcionamento destas instâncias e no atendimento que oferecem às mulheres.
\end{abstract}

Estudos realizados em outros estados e/ou municípios do País contribuem para evidenciar alguns dos obstáculos na aplicação da Lei 11.340/2006, oriundos da estrutura e do funcionamento das DEAMs, os quais trazem questões que são recorrentes e se assemelham em contextos geográficos diversos. Em publicação que antecedeu a promulgação da LMP, Debert (2006) já fazia referência aos diferentes formatos e infraestruturas das DDMs, distribuídos em estados e cidades de tamanhos variados, bem como ao apoio diferenciado recebido pelos poderes legislativo, executivo (municipal e estadual) e das Organizações Não Governamentais. Além disso, a autora destacou que, "[...] sobretudo, o atendimento oferecido depende da convicção política de seus agentes e do modo como estes caracterizam sua clientela e seus interesses", (DEBERT, 2006, p. 22).

Em relatório que "[...] apresenta os resultados da pesquisa Violência Contra a Mulher e Acesso à Justiça, realizada pela CEPIA e que teve como objetivo refletir sobre a efetividade da aplicação da Lei 11.340/2006 - a Lei Maria da Penha." (BARSTED; PITANGUY, 2013, p. 5), realizada em instituições de segurança pública e justiça das capitais Porto Alegre (RS), Recife (PE), Rio de Janeiro (RJ), Salvador (BA) e São Paulo (SP), entre outras questões centrais, foram identificados aspectos estruturais de atendimento, conforme registrado:

Quanto às estruturas - assim compreendidas as edificações e recursos materiais - os problemas existentes não foram apontados nas entrevistas como impeditivo para a realização dos trabalhos. As piores condições foram 
encontradas nas delegacias onde edifícios deteriorados e espaços de atendimento para as mulheres ainda não atendem às recomendações da Norma Técnica de Padronização das DEAMS. (BARSTED; PITANGUY, 2013, p. 62).

Pesquisas realizadas em outras regiões também identificaram questões relacionadas a condições estruturais e à localização das DEAMs. O estudo etnográfico realizado em uma DEAM, inaugurada na década de 1990 na região do Vale do Paraíba/SP, evidenciou sua atual localização nos fundos de um prédio com outras delegacias e, "[...] por sua posição espacial, que, para muitas das interlocutoras indicava desprestígio, era comum ouvir o termo 'delegacia dos fundos'." (FRUGOLI et al., 2019, p. 204). A situação descrita no estudo instiga indagar sobre as condições estruturais que reafirmam o lugar secundário destinado às políticas de enfrentamento das violências contra as mulheres nas agendas governamentais.

Sendo assim, retomando a discussão sobre a estrutura e o modelo de DPCAMI adotados pelo estado de Santa Catarina, é possível questionar se a inexistência de delegacias que atuem especificamente no atendimento às mulheres em situação de violência pode interferir na condução do atendimento, tal como disposto nas Normas Técnicas de Padronização das Delegacias Especializadas de Atendimento às Mulheres (DEAMs), a partir da Lei 11.340/2006. Conforme disposto no Art. $8^{\circ}$ da LMP, em seu inciso "IV - a implementação de atendimento policial especializado para as mulheres, em particular nas Delegacias de Atendimento à Mulher", (BRASIL, 2006). Por conseguinte, problematiza-se a ausência de delegacias especializadas que atendam exclusivamente as mulheres no sentido de atentar para um atendimento especializado no tocante à acolhida das mulheres em situação de violência, na medida em que requer a preparação e o aparelhamento da polícia civil para outros atendimentos.

Tais aspectos podem trazer dificuldades em relação ao ideal de atendimento especializado, individualizado e para a acolhida das mulheres no momento do registro da ocorrência de situações de violência, conforme prevê a própria Lei Maria da Penha.

No que se refere ao seguimento das Normas Técnicas de Padronização das Delegacias Especializadas, por meio da pesquisa que realizaram, Oliveira e Ghisi (2019, p. 12) concluem que,

[...] apesar de a Polícia Civil catarinense ser pioneira na inauguração da Delegacia de Proteção à Mulher no Estado de Santa Catarina, há muito o que adequar em termos de organização administrativa, regulamentação de atribuições e estruturação das unidades perante a Norma Técnica. 
Entre outras fragilidades centrais que comprometem o atendimento a mulheres em situação de violência que procuram as delegacias, Oliveira e Ghisi (2019) ainda apontam para a predominância de delegados homens, defasagens na formação envolvendo questões de gênero, relação com a rede de atendimento, atendimento e serviços ofertados às mulheres, além de estrutura física e equipamentos das unidades de forma deficitária.

No entanto, o avanço precisa ser destacado, pois a existência de pelo menos uma Delegacia de Atendimento às Mulheres para cada DRP (Delegacia Regional de Polícia) demonstra uma política pública diferenciada para o atendimento de mulheres em situação de violência. Quanto à instalação de unidades, de acordo com as informações disponíveis no site da Polícia Civil de Santa Catarina (2019), em Santa Catarina, o total é de 31 DPCAMls, as quais atendem praticamente todas as Delegacias Regionais do Estado de Santa Catarina, dispostas em cinco regiões: Grande Florianópolis, Oeste catarinense, Serrana, Norte, Sul e o Vale do Itajaí; à exceção de Delegacias Especializadas por DRPs está em Laguna/SC, que possui uma Delegacia Regional, mas não possui Delegacia Especializada de Atendimento à Mulher. Em Santa Catarina, as DPCMls estão localizadas nos municípios de Florianópolis, São José, Joinville, Blumenau, Itajaí, Tubarão, Criciúma, Rio do Sul, Lages, Mafra, Caçador, Joaçaba, Chapecó, São Miguel do Oeste, Concórdia, Jaraguá do Sul, Xanxerê, Brusque, Laguna, Araranguá, Ituporanga, São Bento do Sul, Canoinhas, Porto União, Curitibanos, Videira, Campos Novos, São Joaquim, São Lourenço D'Oeste, Balneário Camboriú e Palhoça.

\section{CONSIDERAÇÕES FINAIS}

Após anos de mobilizações e enfrentamentos, no Brasil e em outros países, as lutas pelo fim das violências contra as mulheres foram visibilizadas. No Brasil, como parte de uma trajetória de lutas dos movimentos feministas e de mulheres, articulados em âmbitos nacional e internacional, a criação e a aprovação da Lei 11.343/2006, como visto ao longo do texto, é considerada um marco no enfrentamento e na luta pelo fim da violência doméstica e familiar contra as mulheres. Certamente, a potência e a efetividade da referida Lei estão atreladas a um conjunto mais amplo de políticas públicas, por meio das quais a violência contra as mulheres possa ser enfrentada e combatida. 
A necessária articulação de políticas públicas se revela na estrutura da Lei e seu alcance, sobretudo no âmbito das Delegacias Especializadas de Atendimento às Mulheres (DEAMS), foco do texto ora apresentado. Em Santa Catarina, as Delegacias Especializadas foram implementadas em municípios das cinco grandes regiões do Estado (Grande Florianópolis, Norte do Estado, Oeste catarinense, Região Serrana e Sul do Estado). Contudo, a estrutura do estado catarinense é constituída por um modelo que atende mulheres, crianças, adolescentes e idosos.

A política pública de atendimento, focada nas Delegacias Especializadas em Santa Catarina, gera reflexões, dentre elas saber que se trata de um importante caminho procurado pelas mulheres em situação de violência que podem ceifar o ciclo da violência, razão pela qual precisam de uma atenção especial do Estado e no caso de Santa Catarina. Não obstante ser o segundo estado a implantar uma Delegacia da Mulher no Brasil, conflita com a Lei 11.340/2006, em seu artigo $8^{\circ}$, V, quando não proporciona o atendimento apenas de mulheres, mas de outras populações igualmente importantes. Em razão da aglutinação do atendimento, pode limitar a política pública voltada ao enfrentamento da violência contra as mulheres, sabendo que uma vez registrada a ocorrência, a vida da mulher em situação de violência doméstica mudará, mas para isso precisará do suporte necessário do Estado para, principalmente, não perder o seu maior bem, ou seja, sua própria vida. 


\section{REFERÊNCIAS}

BANDEIRA, Lourdes Maria. Violência de gênero: a construção de um campo teórico e de investigação. Soc. Estado, Brasília, v. 29, n. 2, p. 449-469, ago. 2014. Disponível em: http://www.scielo.br/scielo.php?script=sci arttext\&pid=S010269922014000200008\&lng=pt\&nrm=iso Acesso em: 18 maio 2019.

BANDEIRA, Lourdes Maria; ALMEIDA, Tânia Mara Campos de. Vinte anos da Convenção de Belém do Pará e a Lei Maria da Penha. Rev. Estud. Fem., Florianópolis, v. 23, n. 2, p. 501-517, ago. 2015. Disponível em:

http://www.scielo.br/scielo.php?script=sci arttext\&pid=S0104026X2015000200501\&lng=en\&nrm=iso Acesso em: 30 maio 2018.

BARSTED, Leila. Lei Maria da Penha: uma experiência bem-sucedida de advocacy feminista. In: CAMPOS, Carmen Hein de (Org.). Lei Maria da Penha comentada na perspectiva jurídico-feminista. Rio de Janeiro: Lumen Juris, 2011, p. 13-37. Disponível em: https://assets-compromissoeatitudeipg.sfo2.digitaloceanspaces.com/2014/02/LMP editado final.pdf Acesso em: 10 out. 2018.

BARSTED, Leila Linhares; PITANGUY, Jacqueline (Coord.). Violência contra a mulher e acesso à justiça. Estudo comparativo sobre a aplicação da Lei Maria da Penha em cinco capitais. Relatório final. Rio de Janeiro: Cepia, 2013. Disponível em: https://assetscompromissoeatitudeipg.sfo2.digitaloceanspaces.com/2013/11/CEPIA PesqVCMulh ereAcessoaJustica out2013.pdf Acesso em: 06 ago. 2019.

BRASIL. Lei $n^{0} 11.340$, de 7 de agosto de 2006. Cria mecanismos para coibir a violência doméstica e familiar contra a mulher, nos termos do $\S 8^{\circ}$ do art. 226 da Constituição Federal, da Convenção sobre a Eliminação... Brasília, DF, 2006. Disponível em: http://www.planalto.gov.br/ccivil 03/ ato20042006/2006/lei//11343.htm Acesso em: 26 jul. 2018.

BRASIL. Secretaria Especial de Políticas para as Mulheres. I Plano Nacional de Políticas para as Mulheres. Brasília: Secretaria Especial de Políticas para as Mulheres, 2004.

BRASIL. Secretaria Especial de Políticas para as Mulheres. II Plano Nacional de Políticas para as Mulheres. 2. Reimpressão. Brasília: Secretaria Especial de Políticas para as Mulheres, 2008. 
BRASIL. Secretaria Especial de Políticas para as Mulheres. III Plano Nacional de Políticas para as Mulheres. Brasília: Secretaria de Políticas para as Mulheres, 2013.

BRASIL. Secretaria Especial de Políticas para as Mulheres. Norma Técnica de Padronização das Delegacias Especializadas de Atendimento às Mulheres DEAMs. Brasília/DF, 2010.

BRASIL. Secretaria Especial de Políticas para as Mulheres. Rede Enfrentamento à Violência contra as Mulheres. Brasília, 2011a. Disponível em: https://www12.senado.leg.br/institucional/omv/entenda-a-violencia/pdfs/rede-deenfrentamento-a-violencia-contra-as-mulheres Acesso em: 09 mar. 2019.

BRASIL. Secretaria Especial de Políticas para as Mulheres. Secretaria Nacional de Enfrentamento à Violência contra as Mulheres. Pacto Nacional pelo Enfrentamento à Violência contra as Mulheres. Brasília: Secretaria de Políticas para as Mulheres, 2011b.

BRASIL. Secretaria Especial de Políticas para as Mulheres. Secretaria Nacional de Enfrentamento à Violência contra as Mulheres. Política Nacional de Enfrentamento à Violência Contra as Mulheres. Brasília: Secretaria de Políticas para as Mulheres, 2011c.

CALAZANS, Myllena; CORTES, láris. O processo de criação, aprovação e implementação da Lei Maria da Penha. In: CAMPOS, Carmem Hein de (Org.). Lei Maria da Penha comentada em uma perspectiva jurídico-feminista. Rio de Janeiro: Lumen Juris, 2011, p. 39-63. Disponível em: https://assetscompromissoeatitudeipg.sfo2.digitaloceanspaces.com/2014/02/LMP editado final.p df Acesso em: 10 out. 2018.

CAMPOS, Carmen. Lei Maria da Penha: necessidade de um novo giro paradigmático. Rev. Bras. Segur. Pública, São Paulo, v. 11, n. 1, p. 10-22, 2017. Disponivel em: http://revista.forumseguranca.org.br/index.php/rbsp/article/view/778 Acesso em: 09 out. 2018.

CAMPOS, Carmen Hein de. A CPMI da Violência contra a Mulher e a implementação da Lei Maria da Penha. Rev. Estud. Fem., Florianópolis, v. 23, n. 2, p. 519-531, 2015. Disponível em: http://www.scielo.br/scielo.php?script=sci arttext\&pid=S0104026X2015000200519\&lng=en\&nrm=iso Acesso em: 09 mar. 2019. 
DA ROSA, Leandro Alfredo. Lei 11.340/2006 e políticas de atendimento a mulheres em situação de violência doméstica e familiar no âmbito das delegacias especializadas em Santa Catarina. Dissertação (Mestrado) Universidade do Extremo Sul Catarinense, Programa de Pós-Graduação em Desenvolvimento Socioeconômico, Criciúma, 2019.

DEBERT, Guita Grin. As delegacias de defesa da mulher: judicialização das relações sociais ou politização da justiça? In: CORRÊA, Mariza; SOUZA, Érica Renata de (Orgs.). Vida em família: uma perspectiva comparativa sobre "crimes de honra". Campinas, SP: Pagu-Núcleo de Estudos de Gênero/Universidade Estadual de Campinas, 2006, p. 15-38. Disponível em:

http://www.bibliotecadigital.unicamp.br/document/?down=50807

Acesso em: 31 jul. 2019.

DEBERT, Guita Grin; GREGORI, Maria Filomena. Violência e gênero: novas

propostas, velhos dilemas. Rev. Bras. Ci. Soc., São Paulo, v. 23, n. 66, p. 165-185, fev. 2008. Disponível em:

http://www.scielo.br/scielo.php?script=sci arttext\&pid=S0102-

69092008000100011\&lng=pt\&nrm=iso Acesso em: 19 maio 2019.

DEBERT, Guita Grin; GREGORI, Maria Filomena. As Delegacias Especiais de Polícia e o projeto Gênero e Cidadania. In: CORREAA, Mariza (Org.). Gênero e cidadania. Campinas: Pagu/Núcleo de Estudos de Gênero-Unicamp, 2002, p. 9-19. Disponível em: www.bibliotecadigital.unicamp.br/document/?down $=50798$ Acesso em: 31 jul. 2019.

FARAH, Marta Ferreira Santos. Gênero e políticas públicas. Rev. Estud.

Fem., Florianópolis, v. 12, n. 1, p. 47-71, abr. 2004. Disponível em:

http://www.scielo.br/scielo.php?script=sci arttext\&pid=S0104-

026X2004000100004\&lng=en\&nrm=iso. Acesso em: 30 maio 2018.

FRUGOLI, Rosa et al. De conflitos e negociações: uma etnografia na Delegacia

Especializada de Atendimento à Mulher. Saúde Soc., São Paulo, v. 28, n. 2, p. 201214, 2019. Disponível em:

http://www.scielo.br/scielo.php?script=sci arttext\&pid=S0104-

12902019000200016\&lng=en\&nrm=iso Acesso em: 06 ago. 2019.

NICHOLSON, Linda. Interpretando o gênero. Revista Estudos Feministas.

Florianópolis, CFH/CCE/UFSC, v. 8, n. 2, p. 09-41, 2000. Disponível em:

https://periodicos.ufsc.br/index.php/ref/article/view/11917. Acesso em: 01 ago. 2019. 
OBSERVATÓRIO PELA APLICAÇÃO DA LEI MARIA DA PENHA - OBSERVE. Condições para aplicação da Lei 11.340/2006 (Lei Maria da Penha) nas Delegacias Especializadas de Atendimento à Mulher (DEAMs) e nos Juizados de Violência Doméstica e Familiar nas capitais e no Distrito Federal: Relatório Final. Salvador: Observe, 2010. Disponível em: http://www.observe.ufba.br/ ARQ/Relatorio\%20apresent\%20e\%20DEAMs.pdf Acesso em: 20 abr. 2019.

OLIVEIRA, Ana Claudia Delfini Capistrano de; GHISI, Ana Silvia Serrano. Norma Técnica de Padronização e as Delegacias das Mulheres em Santa Catarina. Rev. Estud. Fem., Florianópolis, v. 27, n. 1, e46855, 2019. Disponível em: http://www.scielo.br/scielo.php?script=sci arttext\&pid=S0104026X2019000100204\&lng=pt\&nrm=iso Acesso em: 09 mar. 2019.

PASINATO, Wânia. Delegacias de Defesa da Mulher e Juizados Especiais Criminais: mulheres, violência e acesso à justiça. Plural, v. 12, p. 79-104, 4 dez. 2005. Disponível em: http://www.revistas.usp.br/plural/article/view/75673/79225 Acesso em: 01 ago. 2019.

POLÍCIA CÍVIL. Delegacia Geral da Polícia Civil de Santa Catarina. Delegacias Especializadas. Disponível em: http://www.pc.sc.gov.br/informacoes/delegaciasespecializadas Acesso em: 06 mar. 2019.

SANTOS, Cecília MacDowell. Curto-circuito, falta de linha ou na linha? Redes de enfrentamento à violência contra mulheres em São Paulo. Rev. Estud.

Fem., Florianópolis, v. 23, n. 2, p. 577-600, ago. 2015. Disponível em: http://www.scielo.br/scielo.php?script=sci arttext\&pid=S0104026X2015000200577\&lng=pt\&nrm=iso Acesso em: 24 maio 2019.

SANTOS, Cecília MacDowell. Da delegacia da mulher à Lei Maria da Penha: absorção/tradução de demandas feministas pelo Estado. Revista Crítica de Ciências Sociais, n. 89, p. 153-170, 2010. Disponível em:

https://journals.openedition.org/rccs/3759. Acesso em: 31 jul. 2019.

SOUZA, Celina. Políticas Públicas: uma revisão da literatura. Sociologias, Porto Alegre, n. 16, p. 20-45, jul./dez. 2006. Disponível em:

http://www.scielo.br/pdf/soc/n16/a03n16 Acesso em: 03 jun. 2018.

SOUZA, Lídio de; CORTEZ, Mirian Beccheri. A delegacia da mulher perante as normas e leis para o enfrentamento da violência contra a mulher: um estudo de caso. Rev. Adm. Pública, Rio de Janeiro, v. 48, n. 3, p. 621-639, 2014. Disponível em: http://www.scielo.br/scielo.php?script=sci arttext\&pid=S003476122014000300005\&lng=en\&nrm=iso Acesso em: 09 mar. 2019. 
WAISELFISZ, Júlio Jacobo. Mapa da violência 2015: Homicídio de mulheres no Brasil. [S.I.]: Cebela/Flacso Brasil, 2015. Disponível em

http://mapadaviolencia.org.br/pdf2015/MapaViolencia 2015 mulheres.pdf Acesso em: 31 jul. 2019. 